\title{
The International Journal of Rural Criminology
}

\section{Editor's Introduction}

This is the second issue of IJRC, a mundane achievement to be sure. What is not so ordinary is the panoply of top-flight scholars who have contributed to the five articles in this edition of IJRC. The lead article, by Maria Kaylen and William Pridemore, is a thorough analysis and critique of social disorganization theory and its application to the study of the social and economic characteristics of rural communities and crime. Almost as if it was written in tandem with the Kaylen and Pridemore article is a synergistic attempt to combine features of social disorganization theory and the theory of civic community to examine variations in FBI crime and arrest rates across four kinds of counties in the US, from the most urban to the most rural. This article, by Edward Wells and Ralph Weisheit, includes nearly every county in the US. Taking a different tack, Walter DeKeseredy, Molly Dragiewicz and Callie Rennison employ data from the National Crime Victimization study to examine possible racial/ethnic variations in violence against women in urban, suburban and rural settings. Next in the queue is a thought-provoking article about environmental justice by Rob White on land theft as a type of "eco-crime." In this article, White argues for a serious consideration of the ways that corporations, local elites and governments often expropriate land for profit and the environmental consequences of land grabbing. The final article, by Matthew Filteau, applies defiance theory to examine the narratives of both poachers and game wardens, utilizing their stories to provide insights for the deterrence of illegal hunting and fishing. Readers may notice a gap in the page numbering between the articles by Rob White and Matthew Filteau. This is due to a last minute request by an author to withhold a manuscript which previously had been accepted.

To reiterate the announcement found in the first issue, The International Journal of Rural Criminology will publish articles both qualitative and quantitative, and from a variety of theoretical perspectives. A key deficiency of past rural crime scholarship is its mostly descriptive, atheoretical nature. This hinders the generalizability of results from rural research, stifles incorporation of the rural into mainstream criminological literature, and precludes the possibility of discovering defects, both conceptual and substantive, within classic forms and contemporary expressions of criminology theory, whose origins, considerations, and applications remain largely focused on the urban context.

Submissions that deal with rural crime issues beyond a few "English-speaking” countries are most appreciated. The goal is to be truly international, and not dominated by rural crime scholarship solely within the Australian, British, Canadian, and US contexts. Readers should keep in mind that nearly 50 percent of the world's population is rural, a percentage that far exceeds the proportion of rural-focused articles in mainline criminology journals.

Finally, this journal's editorial focus does not attempt to restrict submissions in any way other, except that a manuscript must be mainly focused on issues of crime and criminal justice in the 
rural context. Merely putting the word "rural" in the title and then ignoring the cultural, economic, human, political and social dimensions of rural crime is a form of tokenism insufficient to merit consideration for publication in IJRC.

The goal is to publish the International Journal of Rural Criminology at least twice, and possibly four times, each year. Submissions are most welcome at any time, and readers even more so! Manuscripts of any length are welcome, but as a general guideline, submissions should be no longer than 12,000 words (including tables, references, and endnotes). I strongly suggest that prospective authors submit original drafts that adhere to a formatting style for text and for citations as found in the current set of articles.

Submitted: November 30, 2012

Joseph F. Donnermeyer, Editor

Professor of Rural Sociology

Environmental Social Sciences Program

School of Environment and Natural Resources

The Ohio State University

Room 408C, Kottman Hall

2021 Coffey Road

Columbus, Ohio, USA 43210

0106142929167

Dr. Elaine Barclay, Associate Editor

Senior Lecturer in Criminology

Coordinator of Bachelor of Criminology

School of Behavioural, Cognitive and Social Sciences

University of New England

Armidale, New South Wale 2351

Australia

ebarclay@une.edu.au

61267732014
Daniel W. Phillips III, Associate Editor

Associate Professor, Sociology \& Criminal Justice

Chair, Division of Social Sciences

Lindsey Wilson College

210 Lindsey Wilson Street

Columbia, KY USA 42728

phillipsd@lindsey.edu

$010270384-8231$

Ralph Weisheit, Associate Editor

Distinguished Professor

Department of Criminal Justice Sciences

Schroeder Hall E430

Illinois State University

Normal, Illinois USA 61790

raweish@ilstu.edu

0103094383849

Darryl S. Wood

Associate Professor

Criminal Justice, College of Liberal Arts

Multimedia (VMMC) 102W

Washington State University, Vancouver

14204 NE Salmon Creek Avenue

Vancouver, Washington USA 98686

0103605469640 